\title{
Oceanic organic carbon as a possible driver of small-scale (periodic) carbon cycle shifts in the Mesozoic
}

\author{
R.L. SiLVA ${ }^{1,2}$, M. RUHL ${ }^{1,2}$, L.V. DUARTE ${ }^{3}$, S.P. \\ HESSELBO $^{4}$
}

${ }^{1}$ Department of Earth Sciences, Trinity College Dublin, The University of Dublin, Dublin, Ireland

${ }^{2}$ Irish Centre for Research in Applied Geosciences (iCRAG), Trinity College Dublin, The University of Dublin, Dublin, Ireland

${ }^{3}$ MARE, Department of Earth Sciences, University of Coimbra, Coimbra, Portugal

${ }^{4}$ Camborne School of Mines, University of Exeter, Penryn Campus, Penryn, Cornwall, UK.

One of the most challenging aspects in the study of past and present carbon cycle changes and predicting climate evolution concerns the roles and relative importance of oceanic organic carbon (OOC) and oceanic inorganic carbon (OIC) in the global carbon cycle. Variations in the size and composition of the OOC reservoir have the potential to impact on the atmospheric carbon pool $\left(\mathrm{CO}_{2}\right)$ and, therefore, global climates and Earth System processes. In this study, we examine the possible relationship between OOC (predominantly disolved organic carbon - DOC), small-scale (periodic) carbon cycle perturbations, and climate change in the Mesozoic.

Provokingly, we hypothesise that the addition and removal of carbon from the OOC reservoir via orbitally forced processes (controlling, for example, weathering, organic productivity, and alteration of DOC by photodegradation) modulated atmospheric $\mathrm{pCO}_{2}$ and the isotopic composition of carbon reservoirs in several Mesozoic intervals. We test our hypothesis by using a combination of detailed stratigraphic and geochemical studies with back-ofthe-envelope mass balance calculations to constrain broadly the magnitude and rates of change in the size of the OOC reservoir necessary to explain periodic small-scale $(0.5-2 \%$ ) $\delta^{13} \mathrm{C}$ shifts in the (1) Sinemurian-Pliensbachian, (2) Lower Toarcian, (3) Bathonian-Callovian, and the (4) Lower Cretaceous. 